Florida International University FIU Digital Commons

$1-12-1993$

\title{
The effects of massage therapy on delayed-onset muscle soreness after unaccustomed exercise for healthy, sedentary adults
}

Neal B. Finkelstein

Florida International University

DOI: $10.25148 /$ etd.FI15101402

Follow this and additional works at: https://digitalcommons.fiu.edu/etd

Part of the Physical Therapy Commons

\section{Recommended Citation}

Finkelstein, Neal B., "The effects of massage therapy on delayed-onset muscle soreness after unaccustomed exercise for healthy, sedentary adults" (1993). FIU Electronic Theses and Dissertations. 3326.

https://digitalcommons.fiu.edu/etd/3326 


\section{FLORIDA INTERNATIONAL UNIVERSITY}

Miami, Florida

The Effects of Massage Therapy on Delayed-Onset Muscle Soreness After Unaccustomed Exercise for

Heal thy, Sedentary Adults

by

Neal B. Finkelstein

1993 


\section{ABSTRACT OF THE THESIS}

The Effects of Massage Therapy on Delayed-Onset Muscle Soreness After Unaccustomed Exercise for Healthy, Sedentary Adults

by

Neal B. Finkelstein

Florida International University, 1993

Miami, Florida

Dr. Richard Lopez, Major Professor

This study examined the effects of massage therapy on delayed-onset muscle soreness (DOMS) following unaccustomed exercise in healthy, sedentary adults. Fifteen volunteers between the ages of 23 and 63 performed 100 calf raises followed by 15 minutes of rest. After the rest period, one leg was randomly assigned to receive a 5-minute massage while the other leg received a 5-minute placebo ultrasound treatment. A questionnaire was administered to evaluate DOMS at 24,48 , and 72 hour posttreatment intervals when DOMS reportedly is at its peak. A double blind control was employed so that the examiner was unaware as to which treatments were performed on each leg. A t-test for nonindependent samples was used with significance set at the 0.05 level. There was less DoMs reported in the massaged leg at each interval, however, only a significant reduction in DOMS was reported at the 24 hour posttreatment interval. 
FLORIDA INTERNATIONAL UNIVERSITY

Miami, Florida

The Effects of Massage Therapy on Delayed-Onset Muscle Soreness After Unaccustomed Exercise for

Healthy, Sedentary Adults

by

Neal B. Finkelstein

1993 
(C) Copyright by

Neal B. Finkelstein

1993 
To Professors Richard Lopez, Lorraine Gay, and Leonard Elbaum:

This thesis, having been approved in respect to form and mechanical execution, is referred to you for judgement upon its substantial merit.

I. Ira Goldenberg, vean College of Education

The thesis of Neal B. Finkelstein is approved.

Lorraine Gay

Leonard Elbaum

Richard Lopez, Major Professor

Date of Examination: January 12, 1998

Richard Campbel1, Dean

Division of Graduate Studies

Florida International University, 1993 


\section{DEDICATION PAGE}

I would like to dedicate this thesis to the massage therapy profession. The value of good research to substantiate and validate the benefits of massage therapy is necessary to bring this mode of therapy into the mainstream of sports medicine, exercise sciences, and the other health related fields. It is my hope that other individuals take it upon themselves to research the various benefits of massage therapy and to set up a solid methodology to control for extraneous variables. It is through good research for the massage therapy field that I dedicate this thesis. 


\section{ACKNOWLEDGEMENTS}

I would like to acknowledge the following individuals for their assistance with my thesis:

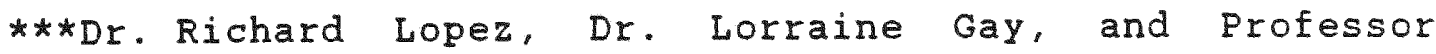
Leonard Elbaum for their assistance and comments as members of my thesis committee;

***Gary Bomzer, Assistant Executive Director for the Dave and Mary Alper Jewish Community Center and Sam B. Nevel for the use of their facilities for my thesis experiment as well as assisting in obtaining the volunteers for my study;

***Steve Grogg, LMT and Kevin Robinson for their time and assistance in administering the 5-minute massage and the 5-minute placebo ultrasound treatment (respectively) for my thesis experiment;

***Adam Sochet, Executive Director of Bodyworks Lifestyle Fitness Centers and Marla Van Meter for the use of their facilities for my pilot study as well as assisting in obtaining volunteers for my pilot study;

***Benny Vaughn, ATC, LMT for giving me the incentive to research the benefits of massage in relation to delayedonset muscle soreness;

$* * *$ All those subjects who volunteered for my study as well as my pilot study for their time and commitment. 
Page \#

Thesis Committee Approval Page............. ii

Dedication Page......................... ii

Acknowledgements.................... iv

List of Figures..................... vi

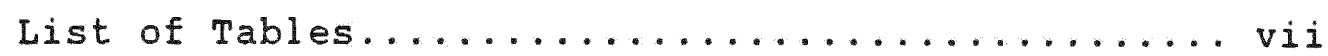

Introduction....................... I

statement of the Problem................. I

Review of the Literature................... 3

Physiological Benefits............... 3

Psychological Benefits............... 7

Performance Benefits................ 8

Statement of the Hypothesis................. 11

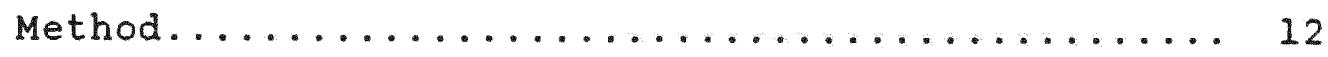

Results.......................... 18

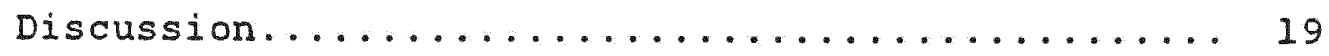

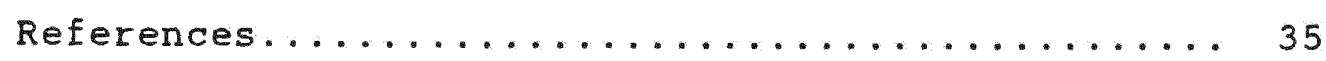




\section{LIST OF FIGURES}

Page \#

Figure 1 (Health status Form)............. 24

Figure 2 (Informed Consent)............. 26

Figure 3 (Subject Preparation Form).......... 28

Figure 4 (Questionnaire).................. 29

Figure 5 (Palpation Points on the Calf Muscle)... 30

Figure 6 (subject Protocol Form)............ 31

Figure 7 (Graph of Results).............. 32 


\section{LIST OF TABLES}

Page \#

Table 1 (Treatment Protocol and Times)......... 33

Table 2 (Posttreatment Means, Standard Deviations, and $\underline{t}$ for the Massaged Leg and the Placebo Ultrasound Treatment Leg)....... 34 


\section{INTRODUCTION}

Massage has been used as a form of healing dating back to 3,000 B.C. (Bean, Henderson, \& Martinsen, 1982; Gallo, 1991; Winant, 1990). Massage therapy has been used for a variety of purposes-from alleviating stress to ameliorating ailments to assisting in sports performance.

While there is considerable testimonial evidence supporting the benefits of massage, there is very little research support for these claims (Cinque, 1989; Lally \& Meyers, 1990; Samples, 1987). As Gallo (1991) stated, massage has the potential to deliver both physical and emotional benefits, but much of the evidence is anecdotal. Samples (1987) contended that many of the claims made for the physiological benefits of massage border on the inaccurate, if not the fraudulent. Therefore, the primary drawback to physician acceptance has been the lack of scientific studies to determine the value of massage. He further stated that some research supporting massage has been done in the (ex) Soviet Union, but the results have not been readily available in English (although this review does quote sources from the soviet sports Review).

\section{STATEMENT OF THE PROBLEM}

The purpose of this study was to investigate the effectiveness of massage with respect to delayed-onset muscle soreness (DOMS). Individuals who have been inactive 
for extended periods of time and engage in sporadic physical exercise, or those who attempt new or unusual types of exercise, often experience severe muscular discomfort 24 to 48 hours following exercise. This condition has been identified in the literature as "delayed-onset muscle soreness--Doms (Yackzan, Adams, \& Francis, 1984; Yates, 1990)." DOMS reaches a peak intensity usually 24-48 hours after unaccustomed exercise and usually lasts from 1 to 5 days (Abraham, 1979; Byrnes, Clarkson, \& Katch, 1985; Maughan, Donnelly, Gleeson, Whiting, Walker, \& Clough, 1989; Yackzan et. al., 1984; Yates, 1990).

There are three main theories surrounding the causes of DOMS (Abraham, 1979; Yackzan et.al., 1984; Yates, 1990). The spasm theory suggests that exercise promotes ischemia which stimulates pain endings in the muscle which results in increased reflex activity of the muscle. This increased reflex activity causes more muscle tension which, in turn, produces more ischemia. The result is a positive feedback cycle of sustained, involuntary muscle contractions--or muscle spasms.

A second theory is the torn tissue theory. This theory states that an untrained muscle group subjected to a prolonged period of work can experience structural damage and change in morphology (i.e. rupture of the muscle fibers). 
The third prominent theory contends that the connective tissue elements of muscle, including tendons are damaged during muscular contractions. This injury induces a localized exudative inflammatory response. The manifestations of the inflammatory response, such as enzyme release and edema formation, result in swelling 24 to 48 hours after exercise. This theory is in part substantiated by the finding that eccentric contractions (negative contractions) are more likely to cause a higher level of soreness than concentric contractions (positive contractions). It is believed that eccentric work places a greater strain on the muscle's elastic components (connective tissues) than concentric work. Byrnes et.al., (1985) substantiated this belief showing DOMS in concentric and eccentric work as opposed to just concentric work which did not result in DOMS.

\section{REVIEW OF THE LITERATURE}

\section{Physiological Benefits}

Several authors have hypothesized that massage has physiological benefits. This implies that it has been substantiated that massage improves the circulation of blood (helping muscle elasticity) and lymph flow (Bean et.al. 1982; Benjamin, 1986; Crosman, Chateauvert, \& Weisberg, 1984; Day, Mason, \& Chesrown, 1987; Gallo, 1991; Lally et.al., 1990; Paikov, 1985; Samples, 1987; stamford, 
1985; Williams, 1990; Winant, 1990; Yates, 1990). Ernst, Matrai, Magyarosy, Liebermeister, Eck, \& Breu (1987) supported this with their study which reported that standard muscular whole body massage induces an acute fall in blood viscosity, the hematocrit, and plasma viscosity. Dubrovsky (1983) also reported that massage promoted acceleration of muscle and venous flow and a reduction of muscle tightness. Arkko, Pakarinen, \& Kari-Koskinen (1983) studied the effects of massage on blood leukocyte and erythrocyte counts, hemoglobin concentration, hematocrit, red cell indices, the activities of serum creatine kinase, lactate dehydrogenase and their isoenzymes, and the concentrations of serum potassium, total protein, haptoglobin, growth hormone, prolactin, cortisol, and plasma corticotropin. The only significant increases were with serum creatine kinase, lactate dehydrogenase and their isoenzymes suggesting an increased permeability of the muscle cells. Thus, massage may result in an outflow of creatine kinase and lactate dehydrogenase from muscle cells as does active muscular work.

This leads us to a second physiological benefit of massage--the elimination of metabolic waste products such as lactic acid (Bean et.a1., 1982; Benjamin, 1986; Cinque, 1989; Crosman et.a1., 1984; Gal10, 1991; Samples, 1987; Stamford, 1985; Williams, 1990; Winant, 1990; Yates, 1990). In Dubrovsky's (1983) study, his results showed that 
massage promoted the acceleration of muscle and venous blood flow and a reduction of muscle tone (tightness) thus resulting in improved oxygen and nutrient supply to the tissues and faster removal of metabolic products from them. On the other hand, winant (1990) pointed out that lactic acid is removed within 20 minutes with an adequate warm down. Therefore, massage is not necessarily a factor in the removal of lactic acid from the body after exercise as long as an adequate warm down is administered.

A third physiological benefit of massage is to promote relaxation of muscles. Muscle massage reduces spasticity thus increasing muscle relaxation (Bean et.al., 1982; Benjamin, 1986; Gal10, 1991; stamford, 1985; Winant, 1990; Yates, 1990). Two studies tried to locate the mechanism responsible for this effect. Day et.al. (1987) explained that the exact mechanism by which massage produces analgesia is not fully understood. They looked at the effect of massage on the peripheral blood levels of endogenous opiates (B-endorphins and B-lipotropins) and did not find any significant increases in healthy adults. Reed \& Held (1988) investigated the effects of connective tissue massage (CTM) on autonomic nervous system (ANS) functioning by measuring its effect on heart rate, galvanic skin response, mean arterial pressure, popliteal skin temperature, and toe skin temperature for healthy middleaged and elderly subjects. CTM showed neither distinct 
acute nor cumulative ANS effects on these measures concluding that CTM may have beneficial effects that are mediated in ways other than through the ANS.

Other physiological benefits of massage are that massage warms the skin (Samples, 1987; stamford, 1985; Winant, 1990; Yates, 1990), it passively stretches muscles and tendons (Crosman et.al., 1984; Gallo, 1991; Samples, 1987; Stamford, 1985; Yates, 1990), reduces edema (Benjamin, 1986; Cinque, 1989; Lally et.al., 1990; Samples, 1987; Stamford, 1985; Winant, 1990; Yates, 1990), aligns subcutaneous scar tissue and breaks up adhesions by way of a direct mechanical effect of applying tension to fibrous tissue allowing further muscular mobility and a reduction of muscle spasm (Bean et.al., 1982; Crosman et.al., 1984; Winant, 1990; Yates, 1990), and is an effective means of fighting fatigue--possibly by improvement in the conduction of nerve

$$
\text { impulses }
$$

(Paikov,

Samples (1987), stamford (1985), winant (1990), and Yates (1990) state that massage warms the skin. A study by Halvorson (1990) looked at the physiologic responses of heat. He stated that heat resulted in increased collagen extensibility and blood flow as well as decreased pain, muscle spasm, and joint stiffness. Further, heat facilitated soft tissue repair through accelerated cellular metabolism and reflex responses to superficial heating of the skin. Local soft-tissue swelling may be reduced 
through improved vascular and lymphatic flow. Range of motion is facilitated through increased extensibility of collagen and reduced muscle spasm. Therefore, it follows that because massage is reported to warm the skin, this effect combined with the mechanical effects of massage and possible warming of the underlying deep muscle and connective tissue, the above effects of heat support the previously mentioned benefits of massage.

\section{Psychological Benefits}

Not only is massage purported to have physiological benefits, it is also believed to have psychological benefits as well. Gallo (1991) stated that we all have an emotional need for touch and that satisfying this need allows the receiver of massage to benefit psychologically. Whitcher \& Fisher (1979) studied the benefits of therapeutic touch. Results indicated that female subjects in the touch condition experienced more favorable affective, behavioral, and physiological reactions than a no-touch control group. However, males in the touch condition reacted more negatively than control subjects on these dimensions--thus confirming a gender difference. In addition, Clark \& Clark (1984) stated that empirical support for the practice of therapeutic touch is, at best, weak.

Another psychological benefit of massage is that it 
can give a psychological boost to athletes and often that psychological component is the component that makes a champion (samples, 1987; stamford, 1985). Bean et.al. (1982) stated that light stroking massage will stimulate the tactile system and cause mental invigoration. Also, Cinque (1989) stated that after analyzing the data from psychological tests, the athletes who received massage after running five miles had a better outlook on their treatment than athletes on diathermy. However, Wayne Cannon, ATC and supervisor of outpatient physical therapy at North Carolina Baptist Hospital in Winston-Salem doesn"t believe the psychological benefits of massage can be objectively measured (cinque 1989). Lally et.al. suggested a correlation between stress relief and massage. Therefore, while it has been reported that massage may have psychological benefits, the mechanisms responsible for these benefits have yet to be identified.

\section{Performance Benefits}

In addition to the physiological claims and the psychological claims of massage during exercise, it is also reported to benefit athletes prior to, during, and following training (Cinque, 1989; stamford, 1985; Williams, 1990; Yates, 1990). Williams (1990), for example, contended that regular massage actually makes for healthier muscles by pushing lactic acid and metabolic waste products 
out of the muscles and working fresh blood into them. This cleansing and the increase in circulation can help the athlete run hard again sooner. With healthy, wellmaintained muscles, the athlete can train harder and therefore massage can assist in attaining peak performance. Cinque (1989) showed how massage can be applied prior to training, during training, and after training to achieve the physiological and psychological benefits mentioned. Cinque (1989) and Paikov (1985) claimed that muscle recovery is 2 to 3 times greater with massage than passive rest. Stamford (1985) claimed that massage can prevent muscle soreness, but that it is difficult to distinguish between the physiological and psychological benefits.

Other performance claims of massage are that massage increases flexibility (Bean et.al., 1982; Crosman et.al., 1984; Winant, 1990; Yates, 1990), allows the athlete to train harder and to improve performance (Paikov, 1985: Williams, 1990), and can be used to relieve fatigue and increase the physical work capacity of athletes (Dubrovsky, 1983; Krilov, Talishev, \& Burovikh, 1985). Crosman et.al. (1984) found that massage will increase the range of motion in the hamstring muscle group in normal female subjects after a single session, although long term effects ( 7 days post treatment) were found to be insignificant. wiktorssen-Moller, Oberg, Ekstrand, \& Gillquist (1983), on the other hand, compared the effects of general warming up, 
massage, and stretching on range of motion and strength of the quadriceps and hamstring muscles. She found that only range of motion for ankle dorsiflexion was significantly increased after massage. Further, thigh muscle strength was not influenced by the experimental procedures. In addition, it is interesting to note that after massage alone, decreases in strength were noted in the hamstrings when recording at angular velocities of 180 and 30 degrees per second and in the quadriceps isometric recording. Walker, Wells, \& Martin (1990) studied the effects of Rolfing and sports massage on VO2 max, running economy, perceived exertion, lower back-hamstring flexibility, and running mechanics. Rolfing is defined as a technique for reordering the body into a more vertical alignment, balancing the left and right sides, and bringing the pelvis into a more horizontal position. They found no significant change in any of the above mentioned parameters with either Rolfing or sports massage.

Although Wiktorsson-Moller et.al. (1983) and walker et.al. (1990) did not find any significant performance benefits for athletes, other studies show a positive correlation between massage and increased sports performance. Ask, Oxelbeck, Lundeberg, \& Tesch (1987) showed how massage exerts a positive effect on muscle recovery after short-term intense exercise. In this study, a group of 8 cyclists showed about $11 \%$ more leg power after 
following up vigorous exercise with a 10-minute massage than when they alternated exercise and rest. Peshkov (1982) concluded that the use of 10-minute classical and point massage after the first training session promotes improved restoration by the time of the second training session for young gymnasts (14-16 years old).

STATEMENT OF

THE

HYPOTHES IS

There is much opinion and anecdotal evidence advocating the effectiveness of massage. The studies that have been reported indicate that massage may have a positive effect on athletic performance, but the exact mechanisms for these benefits are not completely understood. Delayed-onset muscle soreness occurs after unaccustomed exercise and can inhibit recovery time. Yates (1990) stated that massage is commonly and intuitively used to treat DOMS. However, in his review of the literature, he found no references dealing specifically with this subject. Yates (1990) further explained that the physiological effects of massage that produce relief for patients with DOMS (and muscle strain) are presumably related to the reduction of spasm and swelling, the removal of exudates and metabolic wastes through increased lymph flow, restoration of blood circulation, and prevention of fibrosis. Therefore, it is hypothesized that healthy, sedentary adults who engage in 100 calf raises will report 
less DOMS in the leg which receives a 5 minute massage than the leg that receives a 5 minute placebo ultrasound treatment.

\section{METHOD}

The effects of massage on DoMS was compared to a placebo treatment following unaccustomed exercise. Fifteen volunteers between the ages of 23 and 63 who do not regularly engage in any type of exercise program performed 100 calf raises ( 4 sets of 25 repetitions) using their own body weight as resistance. Set \#I was performed with the toes pointed straight ahead. Set \#2 was performed with the toes pointed outward. Set \#3 was performed with the toes pointed inward. Set \#4 was performed with the toes pointed straight ahead as in set \#1. Each subject performed the calf raises on a step to allow full plantar flexion (standing on tiptoes) as well as full dorsiflexion (to stretch the calf muscle)-thus performing this exercise through a full range-of-motion. Each repetition was performed slowly accentuating the eccentric phase (the lowering of the calf to a stretched position). Eccentric contractions were emphasized because they are believed to induce greater muscle soreness than concentric contractions based on the findings of Byrnes et.al. (1985). Consistent with this premise, Clarkson \& Tremblay (1988) and Yackzan et.al. (1984) both used eccentric contractions of the 
biceps brachii to induce DOMS. There was a 20 second rest interval between each set to allow the subjects to recover from any fatigue as a result of the exercise. An experimenter supervised each subject to make sure that the protocol was followed and to make sure no complications arose during the exercise.

This routine was substantiated by the administration of a pilot study to see if DoMs is induced by performing the 100 calf raises as described above. Three groups were used to determine a selection criteria for the study. The three groups used were: those who exercise their calf muscles regularly, those who exercise regularly, but do not exercise their calf muscles regularly, and those who do not exercise regularly. Results showed that DoMs was induced in all three groups with no significant differences among the groups (using an independent $t$-test with the statistical significance set at $\mathscr{Q}=.05$ ). However, the means of the second group were greater than the means of the first group and the means of the third group were greater than the means of the second group. Furthermore, in the first two groups, there were more instances where no soreness was induced by the exercise regimen. Therefore, because all subjects in the third group (those who engaged in no regular exercise) had soreness induced (as opposed to the first two groups where there were some exceptions) and the means in the third group were higher than those of the 
first two groups (although they were not statistically different), this group of subjects was chosen for this study.

Prior to testing, all subjects filled out a health status form (Figure 1) and a consent form (Figure 2) as required by the University Research Council at Florida International University for research involving human subjects. All volunteers were screened and did not seem to pose any medical risks for this experiment. Once cleared for the experiment, each subject was given a sheet listing what time to show up for the experiment and how to prepare for it. Each subject was asked to bring in a pair of sneakers and to have the backs of their legs uncovered for the treatment portion of the experiment (Figure 3 ).

Arrko et.al. (1983), Crosman et.al. (1984), Day et.al. (1987), Walker et.al. (1990), and Wiktorsson-Moller et.al. (1983) all had one licensed massage or physical therapist perform the massage routine. Reed et.al. (1988) had 2 physical therapists perform the routine and walker et.al. (1990) used a group of certified Rolfers for 1 of the 3 groups used in their experiment (that study had 3 groups--a control group, a massage group, and a Rolfed group). Therefore, for the purposes of this experiment, I licensed sports massage therapist was used in applying massage.

A 5-minute massage routine was randomly administered to one of the 2 legs of the 15 volunteers. Four basic 
massage strokes were used. The first stroke, effluerage, is a gliding, light contact stroke (can also be moderate to deep), usually directed toward the heart to assist with venous and lymph flow (Cinque, 1989). A second stroke, petrissage, involves a grabbing stroke similar to the one used when kneading bread. The muscles are squeezed, compressed, and rolled. Petrissage is used to relax and stretch muscles, mobilize tissue fluids, and create intermuscular motion to stretch adhesions (cinque, 1989). A third stroke, palmar-friction, is a back and forth movement of the palms over the muscle at a 90 degree angle. This stroke resembles an "Indian burn" movement and is used to generate heat (note: this stroke is not defined in the literature as a classical massage stroke, but it is used by the experimenter in his private practice--again for the sole purpose of generating heat). The fourth stroke, cross-broadening strokes, are also performed at a 90 degree angle to the muscle fibers. This stroke begins at the middle of the muscle belly and strokes outward. This is performed with both the palm and/or the thumb and is a moderate to deep stroke. The purpose of this stroke is to spread the muscle fibers apart and to assist in the mechanical and physiological effects of effluerage (Phaigh, 1988). All massage movements were applied distal to proximal in the following sequence: 
Effluerage (1ight-to-moderate)........30 seconds

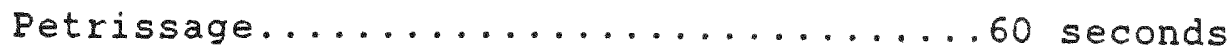

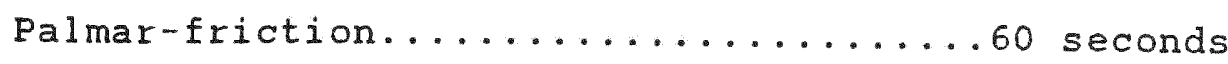

Effluerage (moderate-to-deep)...........30 seconds

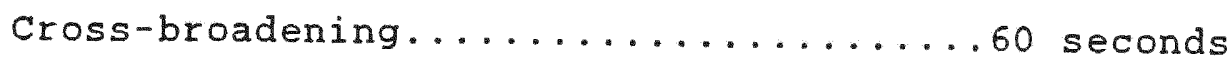

Effluerage (moderate-to-deep)........60 seconds

Acting as a control treatment, the non-massaged leg received a sham ultrasound treatment as used by Reed et.al. (1988). A coupling medium (gel) was used to spread over the area and a non-activated ultrasound transducer moved across the area in a regular pattern of loops. The timer on the ultrasound transducer was activated to duplicate the auditory and visual aspects of ultrasound treatment. Sham ultrasound is analogous to massage in that it provides continuous physical contact with the subject, but the direct, shearing strokes of massage are absent. This serves as a placebo effect and any differences in DOMS would be due to the physiological effects of massage.

The massage application was applied within 1 hour post exercise to achieve a maximal benefit (Krilov et.al., 1985). Paikov (1985) stated that the greatest effect is achieved when massage is applied 10-20 minutes after regular training as soon as pulse and breathing become normal. Therefore, a waiting period of 15 minutes was used before the simultaneous application of the 2 treatments 
(Table 1 shows the cue that each subject went through). Measurement of soreness is a subjective evaluation. Therefore, soreness measurements were assessed by use of a subjective questionnaire (Figure 4) using a ratio scale from 1 (normal) to 5 (sore) to 10 (very, very sore) (Byrnes et.a1., 1985; Clarkson et.a1., 1988; Maughan et.al., 1989; Triffletti, Litchfield, Clarkson, \& Byrnes, 1988). The subjects were asked three questions in which they compared one leg to the other. In the first question they were asked to compare the soreness they experience with each leg while standing on the toes of each foot. Next, they were asked to compare the soreness in each leg while stretching each calf muscle. Finally, the third question had the experimenter palpate 4 sites of the calf. The 4 sites used were at the origin of the calf muscle, the medial point of the calf muscle, and the two insertions of the calf muscle just below the knee (Figure 5). These sites were pressed firmly using moderate pressure. The subjects then were asked to compare the soreness in each leg after the palpation of all 4 sites. These three questions were selected from a base of questions tested in the pilot study mentioned earlier. These questions consistently showed the highest scores in determining DoMs than the other questions and were selected based upon this observation. This would allow a better determination in seeing if there are any significant differences in DoMs between legs through the 
end of the study.

Once the subjects completed the exercise and the treatment, each was given a list of protocols to follow (Figure 6). This was done to try to minimize any differences between subjects in relation to their activities until the conclusion of the study.

A nonindependent $t$-test was used to determine whether the differences between the two legs were significant for the average score of all three questions at 24,48 , and 72 hours posttreatment. These three postreatment intervals were chosen based on the studies of Buroker and Schwane (1989), Maughan et.al. (1989), and Yackzan et.al. (1984) who all studied the effects of DOMS. Statistical significance was set at $\alpha=.05$. A double blind control was employed so that the examiner administering the questionnaire was unaware as to which treatments were performed on each leg. This control was chosen to eliminate any type of experimenter bias while questioning the subjects.

\section{RESULTS}

There was less DOMS in the massaged leg (ML) than the leg which received the placebo ultrasound treatment (PUTL) at the 24,48 , and 72 hour posttreatment intervals (Figure 7). However, only a significant reduction in DOMS was reported at the 24 hour posttreatment interval. Table 2 
shows the means, standard deviations, and t's for the 24, 48, and 72 hour posttreatment intervals. The 24 hour posttreatment interval reported a mean of 3.71 for the $\mathrm{ML}$ as compared to the PUTL at 4.69. This difference was found to be statistically significant. The 48 hour posttreatment interval reported a mean of 4.60 for the ML as compared to the PUTL at 5.49. This difference was less than that of the 24 hour posttreatment interval and was not found to be statistically significant. The 72 hour posttreatment interval reported a mean of 4.36 for the ML as compared to the PUTL at 4.49. Again, the ML reported less DOMS than the PUTL, but the difference was minimal and not statistically significant.

These results show that the massage application had the greatest effect 24 hours after the treatment with its effect diminishing over time.

\section{DISCUSSION}

DOMS after unaccustomed exercise peaks between 24 and 48 hours after exercise (Abraham, 1979; Yackzan et.al., 1984; Yates, 1990). Based upon the results of the pilot study conducted for this experiment, this peak occurred from 24 to 72 hours for all 3 groups who performed the 100 calf raises. This result correlates with the review of the literature on DOMS. There has been some research conducted to study the efficacy of various treatments in reducing 
DoMs. Buroker et.al. (1989) studied the effects of postexercise static stretching in alleviating DOMS and found no significant reduction. Yackzan et.al. (1984) studied the effects of ice massage on DOMS and did not find any significant reduction. This study showed that with a massage application administered 15 minutes after unaccustomed exercise, DOMS can be significantly reduced 24 hours after treatment--although this effect seems to diminish over time.

Paikov (1982) stated that the best treatment for fastest restoration of all body functions is a combination of massage with different therapeutic procedures (such as heat treatment, light therapy, ultrasound, etc.) although there are no studies substantiating this claim. According to Clarkson et.al. (1988), gradual progression is one way of diminishing DOMS. She had 8 college-age women perform 3 eccentric exercises of the forearm flexors. One arm performed 70 maximal contractions and the other arm performed 24 maximal contractions followed 2 weeks later by 70 maximal contractions. Results from this study suggest that an adaptation takes place such that the muscle is more resistant to damage when it has the opportunity to exercise at a lighter load before working with a heavier load and any damage that does occur is repaired at a faster rate.

This study focused on the effects of massage therapy following unaccustomed exercise on the calf muscles of 
healthy, sedentary adults. The results showed that the greatest effects of the massage in reducing DOMS occurred 24 hours posttreatment and this effect diminished over the next couple of days. One possible explanation for this diminishing effect could be from favoring the leg that did not receive the massage treatment--thus putting more pressure on the massaged leg and therefore explaining why the effects of the massage diminished over time.

It is also interesting to point out that the standard deviation on the PUTL increased slightly from 24 to 48 to 72 hours posttreatment whereas the ML had the lowest standard deviation 24 hours posttreatment, but the highest standard deviations at the 48 and 72 hour posttreatment intervals. This may substantiate that the massage treatment had a significant effect on reducing DOMS 24 hours posttreatment, but that other factors, such as the point mentioned above, may have come into play to explain why the effects of massage in reducing DOMS diminished over time. On the other hand, this diminishing effect may have happened naturally. To address this point, a future study using 2 groups of subjects (one massage group and one control group) can study the effects of massage on DOMS without the possibility of favoring one leg over the other. This type of experiment can observe if massage may possibly have a longer reducing effect on DOMS after unaccustomed exercise than this study. 
In choosing a statistical significance at $\alpha=.05$, it is important to note that alpha inflation exists when using multiple t's. This study showed a statistical significance in a reduction of DOMS after 24 hours posttreatment. The $t$ value of 2.60 (compared to the $p$ value at 0.05 of 2.145) indicates that it is not likely that this reduction of Doms in the massaged leg did not happen by chance.

There is much research to be done on methods to diminish DOMS after unaccustomed exercise as there is to address the efficacy of massage therapy on a wide range of topics. Based on the review of the literature, it is my recommendation to those who are sedentary and want to begin an exercise program to begin with light weights before using heavier weights to reduce the effects of DOMS. If, for some reason, the principles of gradual progression are not followed, massage therapy seems to have a significant effect in reducing DOMS only for the first 24 hours or so (if the massage application is given 15 minutes postexercise based on this study). There will not be a significant reduction in DOMS 48 and 72 hours posttreatment with a massage application based upon the results of this study while DOMS perception is still relatively high. Massage will not eliminate DOMS, but it may help alleviate some of the discomfort.

In any case, healthy, sedentary adults who engage in 100 calf raises reported a significant decrease in DOMS in 
the leg which received a 5 minute massage compared to the leg that received a 5 minute placebo ultrasound treatment only at 24 hours posttreatment. Although there was decreased DOMS in the massaged leg as compared to the placebo ultrasound treatment leg at both the 48 and 72 hour posttreatment intervals, these differences were not found to be significant. 


\section{FIGURE 1}

\section{HEALTH STATUS FORM}

SS\# Age Date

Name

Address

Home Phone. Work Phone.

Personal Physician Phone

Sex: Male Female

Race

Height Weight

occupation

Yes No

Has any relative ever had a heart attack before age 60 or any form of cancer?

Do you exercise regularly?

Do you perform any of the following on a regular basis: calf raises, step aerobics, or any other type of calf raising exercises?

- Do you smoke? How many per day?

Do you use alcohol or drugs?

Has a physician ever told you that you had a heart problem?

Do you experience frequent pain or discomfort in your heart or chest?

Do you often feel faint or have spells of severe dizziness?

Were you ever told by a physician that your blood pressure was too high? 
Were you ever told by a physician that you had a bone or joint problem?

Do you have a good reason why you shouldn't exercise?

Explain

Are you over 65 and not accustomed to vigorous exercise?

Are you currently taking medication(s)?

List:

Were you ever told by a physician that you had high blood cholesterol levels?

Do you have or have you had a serious back problem or injury requiring medical treatment?

Do you experience frequent back pain?

How often do you exercise each week?

Is there anything not yet mentioned that you feel that will affect your health or your ability to exercise? Explain:

Please read: I have read and answered all the information above honestly and to the best of my abilities as being true. I have asked any questions that I had and they have been answered to my satisfaction. All information will remain confidential.

Print Name

Signature

Witness

Date 


\section{FIGURE 2}

\section{INFORMED CONSENT}

\section{DESCRIPTION OF ACTIVITIES}

This study is being conducted by Neal B. Finkelstein through Florida International University's Exercise Physiology Department. Graduate advisor is Dr. Richard Lopez 348-2075. The purpose of this research is to look at a certain aspect of exercise and its effect on performance. The expected duration of participation is 5 days. During this 5 day period, all subjects are asked to not engage in any type of exercise--only that type of exercise that is normally part of their daily lives (i.e. walking, but not taking an aerobics class).

\section{RISK}

Subjects participating in this study will experience some discomfort, however, this will only be temporary. All subjects will be adequately supervised. Therefore, any risk associated with this experiment will be kept to an absolute minimum.

\section{BENEFITS}

Although there are no benefits to the subjects directly, your participation in this research may provide helpful information for others. 
CONFIDENT IALITY

All accounts of this research will be kept strictly confidential. Only those people directly associated with the study and Florida International University will have access to the records.

\section{QUESTIONS}

I have the opportunity here to ask questions about anything concerning this procedure and I have done so to my satisfaction.

\section{FREEDOM OF CONSENT}

Participation in this study is voluntary. Refusal to participate will involve no penalty and you may discontinue participation at any time. However, it is encouraged for all participants to complete the 5 day study since the actual experiment is conducted on the first day using the 5 following days for observation. Any further questions may be answered by Dr. Richard Lopez at the phone number above.

I have read this form and having understood the protocols for this study and questions answered, I consent to participate.

Print Name

Signature

Witness

Date 
Thank you for agreeing to participate in my thesis experiment. This experiment will take place on Monday November 9, 1992. Please make arrangements to show up promptly at your assigned times (below) so that we may stay on schedule and not inconvenience others participating in the study. You will need the following for the study:

***a pair of sneakers for the exercise routine;

***for the treatment portion of this experiment, we need to have access to the skin of the back of your lower legs (from the feet to the knees). No invasive treatment wi11 be used.

Name of subject:

Exercise Time:

***about 5 minutes

Treatment Time:

$\star * *$ about 5 minutes

Evaluation Time:

***about 2 minutes

You will receive a list of protocols on the day of the study. Review of this list will take one minute and will be part of the 5 minute exercise routine. This exercise routine has been tested by 3 pilot studies ( 3 practice experiments) and has been found to be effective for the purposes of the research to be conducted. Your normal work clothes and regular makeup will not interfere with the exercise routine (but don't forget the sneakers!).

\section{FOLLOW UP EVALUATION:}

I will need to conduct a 2 minute evaluation from Tuesday through Thursday. This evaluation will take place in the convenience of your office during the morning hours. I will make arrangements to meet with you between $9 \mathrm{a} \cdot \mathrm{m}$. and $11 \mathrm{a} . \mathrm{m}$. If you will not be available during this time, I will make special arrangements with you if necessary.

\section{APPRECIATE YOUR PARTICIPATION IN MY STUDY!}




\section{QUEST IONNAIRE}

Please rate the following questions based on the following scale:

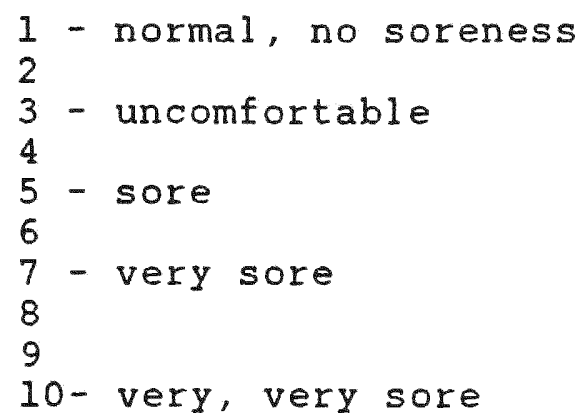

1. Please stand on your toes one leg at a time. How sore does the calf muscle of each leg feel?

Right leg

Left $1 \mathrm{eg}$

2. Please stretch the calf muscles of each leg one leg at a time (see picture below). How sore does the calf muscle of each leg feel?

Right leg

Left 1 eg.

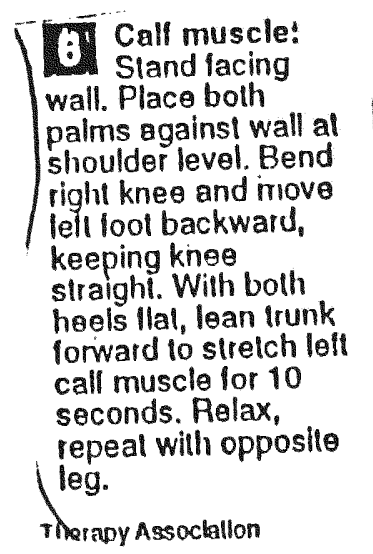

3. Allow the experimenter to press his index finger on the calf muscles of each leg. How sore do they feel?

Right leg

Left $1 \mathrm{eg}$ 


\section{FIGURE 5}

Points used upon palpation for question \#3 of the assessment questionnaire:

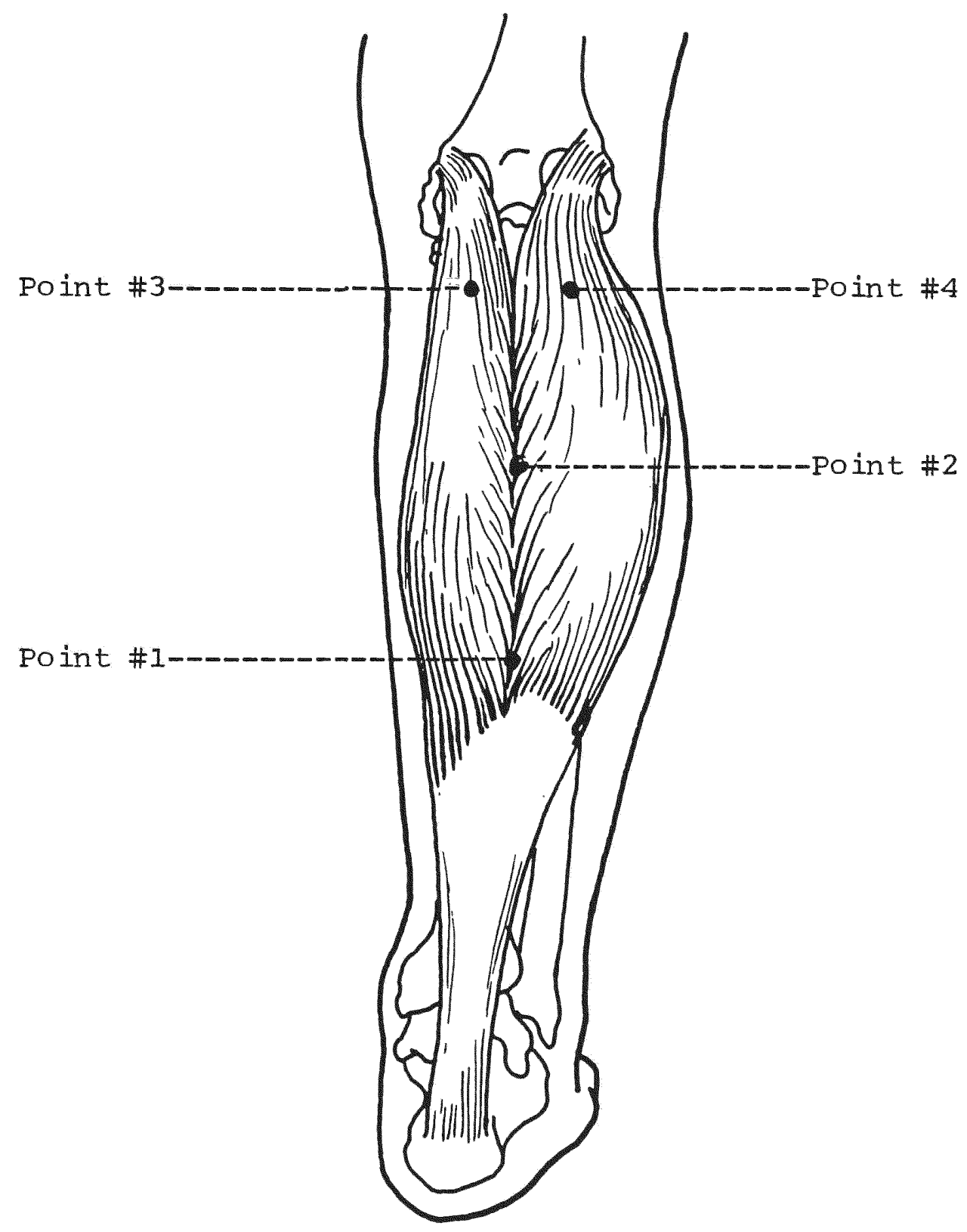




\section{FIGURE 6}

Thank you again for participating in my thesis experiment. For the purposes of proper research, it is important that certain protocols be adhered to throughout the week in order to have minimal variance between subjects. These protocols are listed below:

1. Do not repeat, in any way, the exercise routine you will be performing until the conclusion of this study.

2. Do not discuss this experiment with any other persons besides the experimenter. This includes asking others you may know in the experiment how they answered the items on the questionnaire or how they feel.

3. If you drink alcoholic beverages, please limit yourself to no more than one drink per day as the alcohol may have an effect on your scores.

4. If any out of the ordinary circumstances occur during this week that you feel may have an effect on this experiment, please report this to the experimenter as soon as possible. This would include any blows to the back of the lower leg or any activity that may have an impact on the back of the lower leg.

5. It is encouraged to not take any aspirin, tylenol, antiinflammatory medication, or pain killers throughout the week of this experiment; however, if you need to do so, please notify the experimenter during the daily 2 minute evaluation.

6. Although it is not mandatory, it is encouraged for you to wear comfortable shoes for the week. For the ladies, high heels should be avoided if at all possible.

7. The treatment portion of this experiment will have each leg treated differently. It is imperative that the experimenter have no knowledge of what treatment was performed for each leg.

8. THANK YOU FOR YOUR PARTICIPATION! 


\section{FIGURE 7}

(very, very sore) 10

(very sore)

(uncomfortable)

(normal, no soreness)

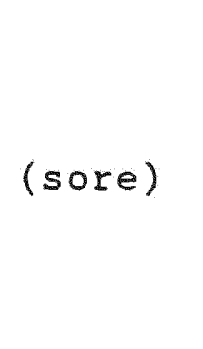

5

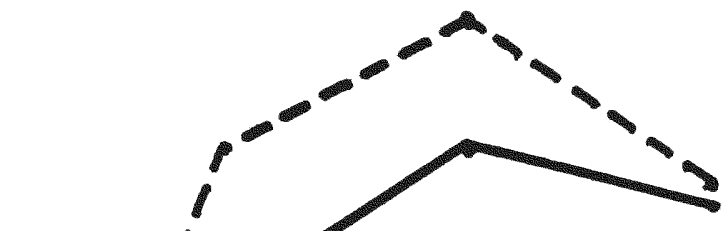

4

(

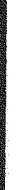


TABLE 1

TREATMENT PROTOCOL AND TIMES

\section{Protocol:}

Heads(H)--Right leg massage, left leg placebo ultrasound. Tails(T)--Left leg massage, right leg placebo ultrasound.

$\begin{array}{cccc}\text { Subject \# } & \text { Exercise } & \text { Treatment } & \text { H/T } \\ 1 & 9: 00 \mathrm{a} \cdot \mathrm{m} . & 9: 20 \mathrm{a} \cdot \mathrm{m} . & \mathrm{H} \\ 2 & 9: 10 \mathrm{a} \cdot \mathrm{m} . & 9: 30 \mathrm{a} \cdot \mathrm{m} . & \mathrm{T} \\ 3 & 9: 20 \mathrm{a} \cdot \mathrm{m} . & 9: 40 \mathrm{a} \cdot \mathrm{m} . & \mathrm{H} \\ 4 & 9: 30 \mathrm{a} \cdot \mathrm{m} . & 9: 50 \mathrm{a} \cdot \mathrm{m} . & \mathrm{T} \\ 5 & 9: 40 \mathrm{a} \cdot \mathrm{m} . & 10: 00 \mathrm{a} \cdot \mathrm{m} . & \mathrm{H} \\ 6 & 9: 50 \mathrm{a} \cdot \mathrm{m} . & 10: 10 \mathrm{a} \cdot \mathrm{m} . & \mathrm{H} \\ 7 & 10: 00 \mathrm{a} \cdot \mathrm{m} . & 10: 20 \mathrm{a} \cdot \mathrm{m} . & \mathrm{T} \\ 8 & 11: 30 \mathrm{a} \cdot \mathrm{m} . & 11: 50 \mathrm{a} \cdot \mathrm{m} . & \mathrm{H} \\ 9 & 11: 40 \mathrm{a} \cdot \mathrm{m} . & 12: 00 \mathrm{p} \cdot \mathrm{m} . & \mathrm{H} \\ 10 & 11: 50 \mathrm{a} \cdot \mathrm{m} . & 12: 10 \mathrm{p} \cdot \mathrm{m} . & \mathrm{T} \\ 11 & 12: 00 \mathrm{p} \cdot \mathrm{m} . & 12: 20 \mathrm{p} \cdot \mathrm{m} . & \mathrm{H} \\ 12 & 12: 10 \mathrm{p} \cdot \mathrm{m} . & 12: 30 \mathrm{p} \cdot \mathrm{m} . & \mathrm{T} \\ 13 & 12: 20 \mathrm{p} \cdot \mathrm{m} . & 12: 40 \mathrm{p} \cdot \mathrm{m} . & \mathrm{T} \\ 14 & 12: 30 \mathrm{p} \cdot \mathrm{m} . & 12: 50 \mathrm{p} \cdot \mathrm{m} . & \mathrm{H} \\ 15 & 12: 40 \mathrm{p} \cdot \mathrm{m} . & 1: 00 \mathrm{p} \cdot \mathrm{m} . & \mathrm{H}\end{array}$


TABLE 2

POSTTREATMENT MEANS, STANDARD DEVIATIONS, AND $t$ FOR THE MASSAGED LEG (ML) AND THE

PLACEBO ULTRASOUND TREATMENT LEG (PUTL)

24 HOUR POSTTREATMENT

$$
\text { ML (a) PUTL (a) } t
$$

Mean

3.71

4.69

$2.60(b)$

Standard Deviation

1.08

1.29

48 HOUR POSTTREATMENT

$\begin{array}{lcc}\text { ML (a) } & \text { PUTL (a) } & \underline{t} \\ 4.60 & 5.49 & 1.74 \text { (c) } \\ 2.17 & 1.60 & \end{array}$

72 HOUR POSTTREATMENT

Mean

Standard Deviation

$$
\text { ML (a) }
$$

4.36

2.15

PUTL (a)

$\underline{t}$

$$
4.49
$$

0.27 (c)

(a) $\underline{n}=15$

(b) $\mathrm{p}<.05$

(c) not significant 


\section{REFERENCES}

Abraham, W.M. (1979). Exercise-induced muscle soreness. Physician and sportsmedicine, 7, 57-60.

Arkko, P.J., Pakarinen, A.J., \& Kari-Koskinen, 0. (1983). Effects on whole body massage on serum protein, electrolyte and hormone concentrations, enzyme activities, and hematological parameters.

International Journal of Sports Medicine, 4 , 265-267. Ask, N., Oxelbeck, U., Lundeberg, T., \& Tesch, P.A. (1987). The influence of massage on quadriceps function after exhaustive exercise. Medicine and Science in sports and Exercise, 19 (2 supplement), 53.

Bean, B., Henderson, H., \& Martinsen, M. (1982). Massage: how to do it and what it will do for you. Scholastic Coach, 52, 10-11+.

Benjamin. J. (1986). Massage: healing or pampering. Dance Magazine, 60,65 .

Buroker, K.C. \& Schwane, J.A. (1989). Does postexercise static stretching alleviate delayed muscle soreness? Physician and sportsmedicine, 17, 65-83.

Byrnes, W.C., Clarkson, P.M., \& Katch, F.I. (1985). Muscle soreness following resistance exercise with and without eccentric contractions. Research Quarterly Eor Exercise and Sport. $56,283-285$. 
Cinque, C. (1989). Massage for cyclists: the winning touch? Physician and Sportsmedicine, 17, 167-170. Clark, P.E. \& Clark, M.J. (1984). Therapeutic touch: is there a scientific basis for the practice? Nursing Research, $33,37-41$.

Clarkson, P.M. \& Tremblay, I. (1988). Exercise-induced muscle damage, repair, and adaptation in humans. Journal of Applied Physiology, 65, 1-6.

Crosman, L.J., Chateauvert, S.R., \& Weisberg, J. (1984).

The effects of massage to the hamstring muscle group on range of motion. Journal of Orthopaedic and sports Physical Therapy, $6,168-172$.

Day, J.A., Mason, R.R., \& Chesrown, S.E. (1987). Effect of massage on serum level of b-endorphin and b-lipotropin in healthy adults. Physical Therapy, 67, 926-930.

Dubrovsky, V.I. (1983). Changes in muscle and venous blood flow after massage. Soviet Sports Review, $1,134-135$. Ernst, E., Matrai, A. , Magyarosy, I., Liebermeister, R.G.A., Eck, M., \& Breu, M.C. (1987). Massage can cause changes in blood fluidity. Physiotherapy, 73 , $43-45$

Gal10, N. (1991). The benefits of massage: ancient relief for today's stresses. Better Homes and Gardens, 69 , $55-58$ 
Halvorson, G.A. (1990). Therapeutic heat and cold for athletic injuries. Physician and Sportsmedicine, 18, 87-94.

Krilov, V.N., Talishev, F.M. \& Burovikh, A.N. (1985). The use of restorative massage in the training of high level basketball players. Soviet sports Review, 20 , 7-9.

Lally, S. \& Meyers, M.S. (1990). Massage: what it can do for you. Prevention, 42, 56-59t.

Maughan, R.J., Donnelly, A.E., Gleeson, M., Whiting, P.H., Walker, K.A., \& Clough, P.J. (1989). Delayed-onset muscle damage and lipid peroxidation in man after a downhill run. Muscle and Nerve, 12, 332-336.

Paikov, V.B. (1985). Means of restoration in the training of speed skaters. Soviet Sports Review, 20, 9-12. Paikov, V.B. (1985). Means of restoration in the training of speed skaters. Soviet sports Review, 20, 98-100. Peshkov, V.F. (1982). The effect of 10-minute restorative point massage on the functional state of young gymnasts. Soviet Sports Review, 17, 148-149.

Phaigh, R. (1988). Therapeutic Massage for Sports and Fitness (102 minute VHS tape). Eugene: Excel sports Science, Inc. 
Reed, B.V. \& Held, J.M. (1988). Effects of sequential connective tissue massage on autonomic nervous system of middle-aged and elderly adults. Physical Therapy, 68 , $1231-1234$

Samples, P. (1987). Does 'sports massage' have a role in sports medicine? Physician and sportsmedicine, 15, $177-183$.

Stamford, B. (1985). Massage for athletes. Physician and Sportsmedicine, 13,178 .

Tappan, F.M. (1980). Healing Massage Techniques: A Study of Eastern and Western Methods. Reston: Reston Publishing Company, Inc.

Triffletti, P., Litchfield, P.E., Clarkson, P.M., \& Byrnes, W.C. (1988). Creatine kinase and muscle soreness after repeated isometric exercise. Medicine and Science in sports and Exercise, 20, 242-247. Walker, J.A., Wells, C.L., \& Martin, P.E. (1990). Effects of rolfing therapy on running economy. Journal of Applied Sports Science Research, 4, 148-153.

Whitcher, S.J. \& Fisher, J.D. (1979). Multidimensional reaction to therapeutic touch in a hospital setting. Journal of Personality and social Psychology, $37,87-$ 96. 